\title{
Validity of summing painful joint sites to assess joint-pain comorbidity in hip or knee osteoarthritis
}

\author{
Liseth Siemons ${ }^{1,5^{*}}$, Peter M ten Klooster ${ }^{1}$, Mart A F J van de Laar ${ }^{1,2}$, Cornelia H M van den Ende ${ }^{3}$ \\ and Thomas J Hoogeboom ${ }^{4}$
}

\begin{abstract}
Background: Previous studies in patients with hip and knee osteoarthritis $(\mathrm{OA})$ have advocated the relevance of assessing the number of painful joint sites, other than the primary affected joint, in both research and clinical practice. However, it is unclear whether joint-pain comorbidities can simply be summed up.

Methods: A total of 401 patients with hip or knee OA completed questionnaires on demographic variables and joint-pain comorbidities. Rasch analysis was performed to evaluate whether a sum score of joint-pain comorbidities can be calculated.

Results: Self-reported joint-pain comorbidities showed a good fit to the Rasch model and were not biased by gender, age, disease duration, BMl, or patient group. As a group, joint-pain comorbidities covered a reasonable range of severity levels, although the sum score had rather low reliability levels suggesting it cannot discriminate well among patients.
\end{abstract}

Conclusions: Joint-pain comorbidities, in other than the primary affected joints, can be summed into a joint pain comorbidity score. Nevertheless, its use is discouraged for individual decision making purposes since its lacks discriminative power in patients with minimal or extreme joint pain.

Keywords: Hip or knee osteoarthritis, Joint-pain comorbidities, Rasch analysis, Sum score, Validity

\section{Background}

Previous studies in patients with hip and knee osteoarthritis (OA) advocated the relevance of assessing the number of painful joints, other than the primary hip or knee joint, in both research and clinical practice [1-3]. Jointpain comorbidities are related - both cross-sectionally and longitudinally - to unfavourable health outcomes, including a higher physical and psychological burden, more severe fatigue, and worse health-related quality of life $[2,3]$.

To date, the use of joint counts to indicate the level of joint-pain comorbidity in people with knee or hip OA is

\footnotetext{
*Correspondence: L.siemons@utwente.nl

'Department of Psychology, Health \& Technology, Arthritis Center Twente, University of Twente, Enschede, The Netherlands

${ }^{5}$ Department of Psychology, Health \& Technology, Faculty of Behavioural Sciences, University of Twente, PO Box 217, 7500, AE, Enschede, the Netherlands

Full list of author information is available at the end of the article
}

common [2-5]. By simply summing up the number of joints that are indicated as painful for more than half of the time during the last month, a fast and easy impression of a patient's overall degree of joint-pain comorbidities is obtained. To determine painful joints, researchers often use written questions or a manikin. Both methods are deemed valid, although the use of a manikin is known to result in a higher prevalence of musculoskeletal pain [6]. Remarkably, however, it remains unclear whether this simple summation of painful joints is actually justified. One could make the argument that this is likely not the case, as summing joints would mean that each of the joint scores assess the same underlying construct and that all joints are of equal importance (i.e. have equal weights) [7].

Therefore, the aim of this study was to examine the validity of summing painful joint sites in people with hip or knee OA.

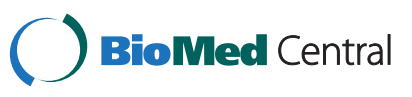

(c) 2013 Siemons et al.; licensee BioMed Central Ltd. This is an Open Access article distributed under the terms of the Creative Commons Attribution License (http://creativecommons.org/licenses/by/2.0), which permits unrestricted use, distribution, and reproduction in any medium, provided the original work is properly cited. 


\section{Methods}

\section{Patients and measures}

Data were used from a previous study, which examined the prevalence of joint-pain comorbidities in patients with a physician-based diagnosis of hip or knee OA [2]. The patients were included if they were 18 years or older and visited an orthopaedic surgeon at the Sint Maartenskliniek (Netherlands) for a new episode of complaints due to hip or knee OA (somewhere between June and October 2009). Patients concurrently suffering from an underlying rheumatic disease were excluded.

At baseline, information was gathered on gender, age, body-mass index (BMI), and disease duration. In addition, the patients received a questionnaire within 14 days after their visit, assessing their joint pain at 19 joint sites, including the hands, wrists, elbows, shoulders, cervical spine, thoracic spine, lumbar spine, hips, knees, ankles, and feet. Patients had to indicate whether they experienced symptoms from particular joints and whether these symptoms were present for more than half of the time during the last month. If both questions were positive, the joint was counted as being painful.

The study was approved by the Institutional Review Board of the University Medical Centre, Nijmegen and all patients enrolled in the study gave informed consent.

\section{Statistics}

\section{Rasch analysis}

Whether the joint-pain comorbidities can simply be summed up was evaluated using Rasch analysis. A feature of the Rasch model is that it assumes all items to be equally discriminating [8]. As a result, a good fit between the Rasch model and the data indicates that individual joint scores can be summed up to obtain a total score of joint-pain comorbidities during the past month [7].

In order to perform Rasch analysis, the data must conform to a number of underlying assumptions of the Rasch model [8-10] including unidimensionality, model fit, and local independence.

The first assumption, unidimensionality, was tested with a principal component analysis of the tetrachoric correlation matrix in SPSS Statistics 18.0, using oblimin rotation. The scale was assumed to be sufficiently unidimensional (i.e. there is one dominant underlying factor) if the ratio of the first and second eigenvalue was $>3: 1$ [11].

The second assumption concerns the model's ability to reflect the true relationship among the underlying construct and the item responses [8-10]. This was tested by evaluation of the mean square Infit (Infit MNSQ) and mean square Outfit (Outfit MNSQ) fit statistics. Mean square values show the ratio between the observed and predicted variance, with an expected value of 1.0 [12]. Corrected for the sample size of 401 patients, the Infit and Outfit ranges required for a good fit are 0.90-1.10 and
0.70-1.30 respectively [13]. Higher values show unexpected responses (noise) or might point to multidimensionality. Lower values point to item redundancy, meaning that the information provided by the item overlaps with the information provided by other items $[12,14,15]$.

The final assumption assumes that the items are not further associated with each other once the Rasch factor is taken into account. Violation of this assumption might point to response dependency (e.g. overlapping items in the scale) or to multidimensionality of the scale $[9,12]$. Items were assumed to be locally dependent if the residual correlation between two items was $>0.5$ [12].

In case the Rasch assumptions were satisfied, joints were checked for differential item functioning (DIF). DIF is present when subgroups of patients with similar levels of the measured underlying construct (i.e. the degree of joint-pain comorbidity as measured by summing the number of painful joints) give different responses (i.e. painful or not painful) to a specific joint $[9,10]$. DIF was tested for age, gender, BMI, disease duration, and patient group. Subgroups of age $(\leq 58$ and $>58)$ and disease duration ( $\leq 10$ years and $>10$ years) were created by splitting the group at the median. BMI subgroups were created by splitting the group at the BMI cut-off point for overweight $(B M I \geq 25)$. Patient groups were formed by separating the knee OA patients from the hip OA patients. In case a patient experienced both knee as well as hip pain, the patient was classified based on their primary complaint.

Finally, the performance of the sum score was examined by evaluating its test information function with associated reliability levels; showing whether precise and reliable joint-pain comorbidity scores can be obtained across the range of joint pain comorbidity severity. Reliabilities $>0.7$ were deemed acceptable for group use [9]. In addition, the higher the test information, the better the test will be able to discriminate among individuals [10].

Rasch analyses were performed using Winsteps, version 3.65 (Winsteps, Chicago, IL, USA).

\section{Results}

\section{Patients}

Data were collected from 401 patients $(58 \%[n=231]$ women and $42 \%$ [n=170] men), of which $71 \%$ were referred for knee OA and $29 \%$ for hip OA. The average (SD) age of the study sample was 58 (13) years, with an average (SD) body mass index of $27(5) \mathrm{kg} / \mathrm{m}^{2}$. The majority of the participants had a K/L grade of $\geq 2$ and a disease duration of $>5$ years, respectively $76 \%$ and $61 \%$. Mean (SD) pain levels were 45 (21) points for the hip group and 50 (20) points for the knee group, as measured with the Hip disability and Osteoarthritis Outcomes Score and Knee Injury and Osteoarthritis Outcome Score respectively [16,17]. More detailed sample characteristics have been described elsewhere $[2,18]$. 
Table 1 Rasch fit statistics of all 19 items $(\mathrm{N}=401)$, with hip scores removed for hip patients and knee scores for knee patients

\begin{tabular}{|c|c|c|c|c|c|c|c|c|c|c|}
\hline \multirow[t]{2}{*}{ Joint } & \multirow{2}{*}{$\frac{\text { Measure }}{\text { Logits }}$} & \multicolumn{4}{|c|}{ Fit } & \multicolumn{5}{|c|}{ DIF } \\
\hline & & Infit MNSQ & Infit ZSTD & Outfit MNSQ & $\overline{\text { Outfit ZSTD }}$ & Age & Gender & BMI & Disease duration & Patient group \\
\hline Lumbar spine & -2.02 & 1.23 & 3.5 & 1.28 & 2.3 & -0.73 & 0.26 & 0.20 & 0.14 & 1.14 \\
\hline Left knee & -1.45 & 1.24 & 1.8 & 1.21 & 1.0 & 1.03 & 1.12 & 0.45 & -0.70 & N/A \\
\hline Right knee & -1.11 & 1.02 & 0.2 & 1.06 & 0.3 & -1.11 & -0.31 & 0.30 & -0.10 & N/A \\
\hline Neck & -0.90 & 1.00 & 0.1 & 1.04 & 0.4 & -0.17 & 0.02 & -0.84 & 0.07 & -0.11 \\
\hline Right shoulder & -0.46 & 1.04 & 0.4 & 1.01 & 0.1 & -0.17 & -0.18 & -0.16 & 0.11 & 0.04 \\
\hline Left shoulder & -0.21 & 0.87 & -1.2 & 0.72 & -1.6 & 0.21 & -0.32 & -0.05 & -0.06 & -0.15 \\
\hline Right hand & -0.10 & 0.95 & -0.4 & 0.99 & 0.0 & 0.99 & -0.53 & -0.05 & -0.23 & -0.65 \\
\hline Left foot & 0.06 & 0.94 & -0.5 & 0.89 & -0.4 & 0.19 & -0.10 & 0.37 & 0.11 & -0.45 \\
\hline Right hip & 0.07 & 1.02 & 0.2 & 1.04 & 0.2 & -0.16 & 0.03 & 0.17 & 0.59 & N/A \\
\hline Left hip & 0.07 & 1.16 & 1.2 & 1.38 & 1.5 & -0.84 & -0.49 & -0.30 & 0.45 & N/A \\
\hline Right foot & 0.10 & 0.94 & -0.5 & 0.77 & -1.1 & 0.11 & -0.03 & -0.12 & -0.46 & 0.08 \\
\hline Left hand & 0.24 & 1.05 & 0.4 & 1.09 & 0.4 & 1.04 & -0.26 & -0.06 & -0.28 & -0.78 \\
\hline Thoracic spine & 0.48 & 1.09 & 0.7 & 0.85 & -0.5 & -0.22 & 0.11 & 0.19 & 0.45 & 0.85 \\
\hline Right ankle & 0.54 & 0.99 & 0.0 & 0.98 & 0.0 & -0.53 & 0.19 & -0.25 & -0.60 & 0.69 \\
\hline Left ankle & 0.59 & 0.89 & -0.7 & 0.67 & -1.3 & -0.21 & -0.77 & 0.10 & -0.21 & -0.69 \\
\hline Right wrist & 0.65 & 0.79 & -1.3 & 0.52 & -1.9 & 0.38 & -0.14 & 0.28 & 0.02 & -0.62 \\
\hline Left wrist & 0.71 & 0.87 & -0.7 & 0.63 & -1.3 & 1.08 & -0.03 & 0.00 & 0.04 & -0.19 \\
\hline Right elbow & 1.11 & 1.09 & 0.5 & 1.33 & 0.9 & -0.46 & 1.57 & 0.66 & 0.38 & -0.99 \\
\hline Left elbow & 1.65 & 0.95 & -0.1 & 0.88 & -0.1 & -0.05 & 0.92 & 0.32 & 0.20 & -1.02 \\
\hline
\end{tabular}

Infit MNSQ: mean square Infit, Outfit MNSQ: mean square Outfit, ZSTD: standardized as a z-score, DIF: differential item functioning, BMI: body-mass index, N/A: not available. Bold values show either Infit MNSQs or Outfit MNSQs outside their specified range or show the presence of differential item functioning (DIF). DIF would have been significant when: $p<\left(0.05 /\left(5^{*} 19\right)\right)=0.000526$ (corrected for sample size) AND when the absolute difference between the two difficulty parameters was $\geq 0.5$ logits. However, no significant DIF results were found in this study.

\section{Rasch analysis}

The test of unidimensionality showed that the ratio between the first and second eigenvalue was $9.701: 2.117$, which is $>3: 1$. Thus, the 19 items formed a sufficiently unidimensional scale for Rasch analysis.

The results of the Rasch analysis showed an acceptable fit of the comorbid joints (i.e. other than the primary affected joints) to the Rasch model (Table 1). Infit MNSQ was $<0.90$ or $>1.10$ for 7 out of the 19 joints and Outfit MNSQ was $<0.70$ or $>1.30$ for only 5 joints. Additionally, none of the items showed DIF and local independence of the items was supported by low inter-item residual correlations $(<0.49)$.

Although some Infit and Outfit values fell outside the specified range for a number of joints, these analyses were based on very strict sample size corrected Infit and

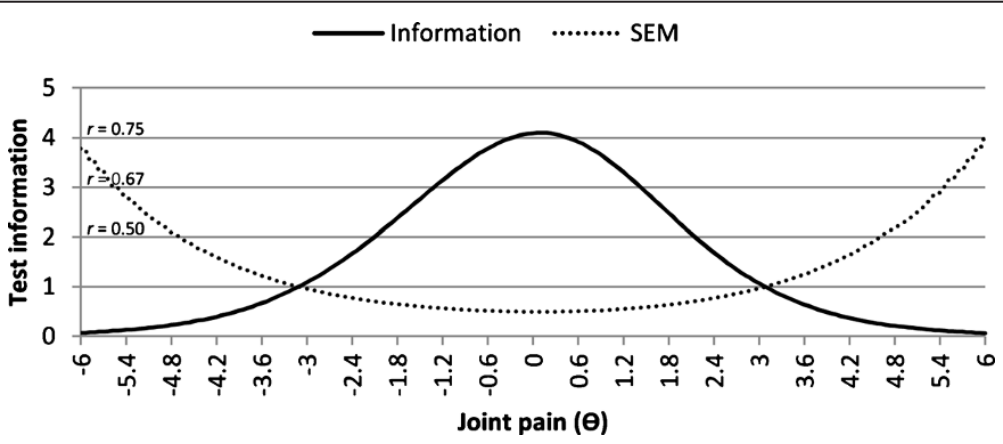

Figure 1 Test information function of the 19 items, with hip scores removed for hip patients and knee scores for knee patients. Its associated reliability level $(r)$ and standard error of measurement (SEM) are included and $\theta$ indicates the latent variable (standardized to a logit score of 0 ). Higher values of $\theta$ indicate a higher number of painful joints. Logit values of $-3,0$, and 3 correspond approximately to total comorbidity scores of 1,9-10, and 18, respectively. 
Outfit statistics. A more commonly applied, less strict, rule of thumb is that both the Infit and the Outfit MNSQ are allowed to be somewhere between the 0.7 and 1.3. When these values were held against the data, fit was even better with none of the joints showing Infit MNSQ values $<0.70$ or $>1.30$ and only 5 joints showing Outfit MNSQ values $<0.70$ or $>1.30$.

The test information function (Figure 1) shows that joint-pain comorbidities covered a reasonable range of joint-pain comorbidity levels. However, its measurement reliability was relatively low with a maximum value of 0.76 . Reliability was only above the minimally required value for group use, $r>0.70$, within a range of -1.04 to +1.18 , corresponding to the presence of 5 to 14 painful joints. Although this indicates that the instrument can discriminate well between patients within these wide range of joint scores, it only covered $11.2 \%$ of the patient sample since most patients (86.8\%) had less than 5 painful joints. The instrument's discriminative power for this large majority of patients with few complaints is much lower, diminishing the instrument's usefulness.

\section{Discussion}

The past decades show a marked increase in item response theory applications within the rheumatic field [19]. Item response theory offers a powerful framework for developing and evaluating patient-reported and clinical measures, item banks, or computerized adaptive tests. In addition, Rasch analysis can be used for examining the validity of a scoring algorithm like the summation of pain scores of individual joints. This study confirms that joint-pain comorbidities, in other than the primary affected joints, can be summed into a joint pain comorbidity score, as frequently used in previous studies in order to determine its association to patients' health states $[2-4,20]$. The absence of DIF across age, gender, disease duration, BMI, and patient group indicates that this measure can validly be used in research. However, even though the analyses confirmed that the instrument can measure a reasonable range of pain comorbidities, the instrument's reliability was rather low and it lacks discriminative power in patients with minimal or extreme joint pain. Therefore, its use is discouraged for individual decision making purposes in clinical practice.

Comorbidity is very common in people with OA $[21,22]$ and is linked to the burden of illness [23]. A better understanding of comorbidity in OA patients might enable us to define new strategies to manage the OA symptoms. Joint pain comorbidity can play an important role in OA since previous studies already demonstrated that higher joint counts in people with OA are associated with less favorable health states $[2,3]$ and worse outcomes after total knee replacement surgery [4]. Now that we demonstrated that joint counts can be validly used in medical research concerning patients with hip and/or knee OA, future studies should further explore joint pain impact and perhaps its manageability [24].

\section{Conclusions}

The results of this study showed that it is valid to sum the number of painful joint sites to assess joint-pain comorbidity in hip or knee osteoarthritis. However, prudence is in order when using this instrument for treatment decisions on an individual level.

\section{Abbreviations \\ OA: Osteoarthritis; BMI: Body mass index; MNSQ: Mean square; DIF: Differential item functioning.}

\section{Competing interests}

None of the authors have financial, commercial, or other associations that might pose a conflict of interest in connection with the work.

\section{Authors' contributions}

LS was responsible for the conceptualization of the manuscript. EVDE and TH were responsible for data collection. PTK, TH, EVDE, and MVDL supervised the whole study and the interpretation of the results. All authors critically evaluated the manuscript, contributed to its content, and approved the final version. LS and TH take responsibility for the integrity of the work as a whole, from inception to finished article (L.siemons@utwente.nl, thomashoogeboom@gmail.com).

\section{Author details}

${ }^{1}$ Department of Psychology, Health \& Technology, Arthritis Center Twente, University of Twente, Enschede, The Netherlands. ${ }^{2}$ Department of Rheumatology, Arthritis Center Twente, Medisch Spectrum Twente, Enschede, The Netherlands. ${ }^{3}$ Department of Rheumatology, Sint Maartenskliniek, Nijmegen, The Netherlands. ${ }^{4}$ Department of Epidemiology, CAPHRI, CCTR; Maastricht University Medical Centre +, Maastricht, The Netherlands. ${ }^{5}$ Department of Psychology, Health \& Technology, Faculty of Behavioural Sciences, University of Twente, PO Box 217, 7500, AE, Enschede, the Netherlands.

Received: 21 February 2013 Accepted: 5 August 2013

Published: 9 August 2013

\section{References}

1. Conaghan PG, Birrell F, Burke M, Cumming J, Dickson J, Dieppe P, et al: Osteoarthritis: national clinical guideline for care and management in adults. London: Royal College of Physicians; 2008.

2. Hoogeboom TJ, den Broeder AA, Swierstra BA, de Bie RA, van den Ende CHM: Joint-pain comorbidity, health status, and medication use in hip and knee osteoarthritis: a cross-sectional study. Arthritis Care Res 2012, 64:54-58.

3. Hoogeboom TJ, den Broeder AA, de Bie RA, van den Ende CHM: Longitudinal impact of joint pain comorbidity on quality of life and activity levels in knee osteoarthritis: data from the osteoarthritis initiative. Rheumatology 2013, 52:543-546.

4. Perruccio AV, Power JD, Evans HM, Mahomed SR, Gandhi R, Mahomed NN, Davis AM: Multiple joint involvement in total knee replacement for osteoarthritis: effects on patient-reported outcomes. Arthritis Care Res 2012, 64:838-846.

5. Castrejón I, Yazici Y, Pincus T: Patient self-report RADAI (rheumatoid arthritis disease activity index) joint counts on an MDHAQ (multidimensional health assessment questionnaire) in usual care of consecutive patients with rheumatic diseases other than rheumatoid arthritis. Arthritis Care Res 2013, 62:288-293.

6. Van den Hoven LH, Gorter KJ, Picavet HS: Measuring musculoskeletal pain by questionnaires: the manikin versus written questions. Eur J Pain 2010, 14:335-338.

7. Andersen EB: Sufficient statistics and latent trait models. Psychometrika 1977, 42:69-81. 
8. Orlando M: Critical issues to address when applying item response theory (IRT) models, Conference on improving health outcomes assessment based on modern measurement theory and computerized adaptive testing. Bethesda, MD: Hyatt; 2004

9. Tennant A, Conaghan PG: The rasch measurement model in rheumatology: what is it and why use it? When should it be applied, and what should one look for in a rasch paper? Arthritis Rheum 2007, 57:1358-1362.

10. Reeve $B B$, Fayers $P$ : Applying item response theory modeling for evaluating questionnaire item and scale properties. In Assessing quality of life in clinical trials: methods of practice. 2nd edition. Edited by Fayers $\mathrm{P}$, Hays RD. Oxford, NY: Oxford University Press; 2005:55-73.

11. Morizot J, Ainsworth AT, Reise S: Toward modern psychometrics: application of item response theory models in personality research. In Handbook of research methods in personality psychology. Edited by Robins RW, Fraley RC, Krueger RFE. New York, NY: Guilford; 2007:407-423.

12. ten Klooster PM, Taal E, van de Laar MA: Rasch analysis of the Dutch health assessment questionnaire disability index and the health assessment questionnaire II in patients with rheumatoid arthritis. Arthritis Rheum 2008, 59:1721-1728.

13. Smith MR, Schumacker RE, Busch MJ: Using item mean squares to evaluate fit to the rasch model. J Outcome Meas 1998, 2:66-78.

14. Wolfe F, van der Heijde DM, Larsen A: Assessing radiographic status of rheumatoid arthritis: introduction of a short erosion scale. J Rheumatol 2000, 27:2090-2099.

15. Tennant A, Kearns S, Turner F, Wyatt S, Haigh R, Chamberlain MA: Measuring the function of children with juvenile arthritis. Rheumatology 2001, 40:1274-1278.

16. de Groot IB, Reijman M, Terwee CB, Bierma-Zeinstra SM, Favejee M, Roos EM, Verhaar JA: Validation of the Dutch version of the hip disability and osteoarthritis outcome score. Osteoarthritis Cartilage 2007, 15:104-109.

17. de Groot IB, Favejee MM, Reijman M, Verhaar JA, Terwee CB: The Dutch version of the knee injury and osteoarthritis outcome score: a validation study. Health Qual Life Outcomes 2008, 6:16.

18. Hoogeboom TJ, de Bie RA, den Broeder AA, van den Ende CHM: The Dutch lower extremity functional scale was highly reliable, valid and responsive in individuals with hip/knee osteoarthritis: a validation study. BMC Musculoskelet Disord 2012, 13:117.

19. Siemons L, ten Klooster PM, Taal E, Glas CAW, van de Laar MAFJ: Modern psychometrics applied in rheumatology - a systematic review. BMC Musculoskelet Disord 2012, 13:216

20. Suri P, Morgenroth DC, Kwoh CK, Bean JF, Kalichman L, Hunter DJ: Low back pain and other musculoskeletal pain comorbidities in individuals with symptomatic osteoarthritis of the knee: data from the osteoarthritis initiative. Arthritis Care Res 2010, 62:1715-1723.

21. Caporali R, Cimmino MA, Sarzi-Puttini P, Scarpa R, Parazzini F, Zaninelli A, Ciocci A, Montecucco C: Comorbid conditions in the AMICA study patients: effects on the quality of life and drug prescriptions by general practitioners and specialists. Semin Arthritis Rheum 2005, 35:31-37.

22. Kadam UT, Croft PR: Clinical comorbidity in osteoarthritis: associations with physical function in older patients in family practice. J Rheumatol 2007, 34:1899-1904

23. Wesseling J, Welsing PM, Bierma-Zeinstra SM, Dekker J, Gorter KJ, Kloppenburg M, Roorda LD, Bijlsma JW: Impact of self-reported comorbidity on physical and mental health status in early symptomatic osteoarthritis: the CHECK (cohort Hip and cohort knee) study. Rheumatology (Oxford) 2013, 52:180-188.

24. Hoogeboom TJ, Stukstette MJ, de Bie RA, Cornelissen J, den Broeder AA, van den Ende $\mathrm{CH}$ : Non-pharmacological care for patients with generalized osteoarthritis: design of a randomized clinical trial. BMC Musculoskelet Disord 2010, 11:142.

doi:10.1186/1471-2474-14-234

Cite this article as: Siemons et al:: Validity of summing painful joint sites to assess joint-pain comorbidity in hip or knee osteoarthritis. BMC Musculoskeletal Disorders 2013 14:234.

\section{Submit your next manuscript to BioMed Central and take full advantage of:}

- Convenient online submission

- Thorough peer review

- No space constraints or color figure charges

- Immediate publication on acceptance

- Inclusion in PubMed, CAS, Scopus and Google Scholar

- Research which is freely available for redistribution

Submit your manuscript at www.biomedcentral.com/submit
() Biomed Central 